\title{
Telemedicine for Patient Management on Expeditions in Remote and Austere Environments: A Systematic Review
}

\author{
Louise Ting, BM BS ${ }^{1}$; Matt Wilkes, $\mathrm{MSc}^{2}$ \\ ${ }^{1}$ Great Western Hospitals NHS Foundation Trust, Swindon, United Kingdom; ${ }^{2}$ Extreme Environments Laboratory, University of Portsmouth, \\ Portsmouth, United Kingdom
}

\begin{abstract}
Telemedicine potentially offers enormous value to expeditions to remote environments. For healthcare professionals, telemedicine can provide access to specialist advice. Where no healthcare professionals are present, telemedicine may be the sole source of expert care. This systematic review appraises and summarizes the current literature regarding telemedicine in patient management on expeditions to remote locations and identifies areas for future research. MEDLINE and EMBASE were systematically searched for relevant articles from 1980 through February 2018. Data were handled according to the PRISMA process and analyzed using type-specific critical appraisal checklists where possible. Two hundred twenty-five articles were identified, 33 of which were included in this systematic review. They encompassed a variety of remote environments, including maritime (13), polar (9), mountainous (5), jungle (1), and multiple austere environments (6). Although some environments were better reported than others, many overarching concepts were generalizable. Through channels of communication that included telephone, radio, videoconferencing, and email, telemedicine has been used effectively in a range of environments to initiate treatment, follow up with patients, and determine the appropriateness of evacuation. Telementoring, in which a remote expert guides a local care provider in performing a procedure or task, is a promising aspect of telemedicine that is currently being developed. As technology advances, the scope of telemedicine will continue to expand. However, each new telemedical development must be shown to do more than simply function in a remote environment. Instead, new technologies should be tested for improved patient, practitioner, or expedition outcomes, within a telemedical system.
\end{abstract}

Keywords: remote consultation, wilderness medicine, telementoring

\section{Introduction}

Telemedicine is the provision of healthcare to patients by a distant provider. ${ }^{1}$ It allows direct patient management without the physical presence of the healthcare professional and enables isolated healthcare providers to access specialist advice. $^{2}$ As the popularity of adventure tourism and expeditions to remote environments grows, ${ }^{3}$ telemedicine may become increasingly prevalent.

From the oceans to the Antarctic, expeditions are undertaken for different purposes in varied settings. ${ }^{3}$ Each location presents different challenges. At sea, ships can be away for long periods of time. Medical

Corresponding author: Louise Ting, BM BS, Swindon Academy, Undergraduate Office, Great Western Hospital, Malborough Road, Swindon, SN3 6BB; e-mail: louise.ting@nhs.net.

Submitted for publication November 2019.

Accepted for publication September 2020. facilities are limited, and there may be no medical personnel onboard. ${ }^{4}$ Evacuation or redirection to healthcare may be possible, but it would often be disruptive and expensive. In contrast, research stations in the Antarctic may have good medical facilities, but evacuation during the winter months is nearly impossible. ${ }^{5}$

This review summarizes the current literature regarding the use of telemedicine to assist in management of patients on expeditions in remote and austere terrestrial locations and identifies areas for future work.

\section{Methods}

\section{SEARCH STRATEGY}

Embase and Medline were systematically searched via Healthcare Databases Advanced Search through February 2018 using the search strings in Table 1. Reference lists 
Table 1. Search terms

\begin{tabular}{ll}
\hline MEDLINE & EMBASE \\
\hline "Telemedicine" [MeSH terms] OR "Tele*" AND & "Telemedicine" [MeSH terms] AND "wilderness \\
"Expedition" [MeSH terms) OR "Wilderness medicine" & medicine" [MeSH terms] OR "travel medicine" \\
[MeSH terms] OR "Extreme environments" [MeSH & [MeSH terms] OR "altitude" [MeSH terms] OR \\
terms] OR "Remote" OR "Polar" OR "Artic" OR & "Mountaineering" [MeSH terms] OR "Expedition" \\
"Antarctic" OR "Mountain" OR "Altitude" [MeSH terms] & OR "Maritime" OR "Polar Ice Cap" [MeSH terms] OR \\
OR "mountaineering" [MeSH terms] OR "desert" OR & "Artic" Or "Antarctic" OR "Desert" Or "Mountain" \\
"Maritime" & OR "Jungle" OR "Austere" OR "Hostile" \\
\hline
\end{tabular}

of full-text publications were hand-sorted to locate other potentially relevant publications. Titles and abstracts were screened for eligibility, and full texts of all articles that appeared relevant were obtained. These were checked against the inclusion and exclusion criteria to generate the final list of publications for review.

\section{INCLUSION CRITERIA}

All reviews, studies, and commentaries published in peerreviewed journals concerning telemedicine and its contribution to diagnosis or patient management in remote or austere environments, such as maritime, polar, mountainous, jungle, or desert environments were included. We used a broad definition of "expedition" that included seafarers, cruise ship passengers, visiting researchers, and military personnel.

\section{EXCLUSION CRITERIA}

This review focused specifically on telemedicine for patients on remote terrestrial expeditions, rather than telemedicine in general. Consequently, articles that mainly focused on telemedicine for disaster medicine, battlefield medicine, aerospace medicine, rural medicine, and chronic disease management in settled populations in remote areas were excluded. Conference abstracts, unobtainable full-text articles, and articles not published in English or published before 1980 were also excluded. Because telemedicine's performance is technologydependent, articles published before 1980 were considered outdated.

\section{METHODS FOR CRITICAL APPRAISAL}

Study type-specific critical appraisal tools were used to review the articles where possible. These included a checklist for critical appraisal of case reports, ${ }^{6}$ the Joanna Briggs Institute checklists for case series, ${ }^{7}$ and the critical appraisal skills program qualitative checklist. ${ }^{8}$ These checklists offered a systematic framework to critically appraise the varied sources of evidence.

\section{Results}

Thirty-four publications were included (Figure 1). Many were of low evidential quality, consisting of case series and reports, pilot studies, and company reports on activities of telemedical programs. Qualitative studies, retrospective studies evaluating existing services for telemedicine, and 1 research proposal were also included. No systematic reviews or randomized control trials regarding the use of telemedicine in remote environments were identified.

The articles included dated from 1995 to 2017. The maritime and Antarctic environments were best represented. No reports focusing solely on desert or Arctic conditions were identified. Table 2 breaks the results down by environment and article type.

Subjects included general use of telemedicine for consultation purposes; use of diagnostic aids such as ultrasound, electrocardiography (ECG), and photography; telementoring; feasibility of equipment operation in austere environments; user satisfaction with telemedical services; and development of telemonitoring equipment (Table 3). ${ }^{9-38}$

The number of patients involved in each article varied according to publication type because many studies involving patients were case reports or case series. Four studies $^{5,20-22}$ included specific cohorts of patients treated within a particular timeframe. One maritime ${ }^{23}$ and 1 Antarctic $^{5}$ report provided data on the number of telemedical consultations undertaken and the incidence of each type of presenting complaint. Of 10,815 patients treated by the Italian telemedical maritime assistance service (TMAS) from 2012 to 2014, abdominal complaints and injuries were the most frequent cause of telemedical consultations, contributing to $17 \%$, respectively. ${ }^{23}$ Data from Japan's Syowa station in the Antarctic found that $45 \%$ of 4932 telemedical consultations from 1956 to 2003 were for injury and trauma. ${ }^{5}$ This type of data could be used to plan equipment provision and recruitment of specialists.

The articles included in this review also illustrated the range of medical equipment and services that have been 


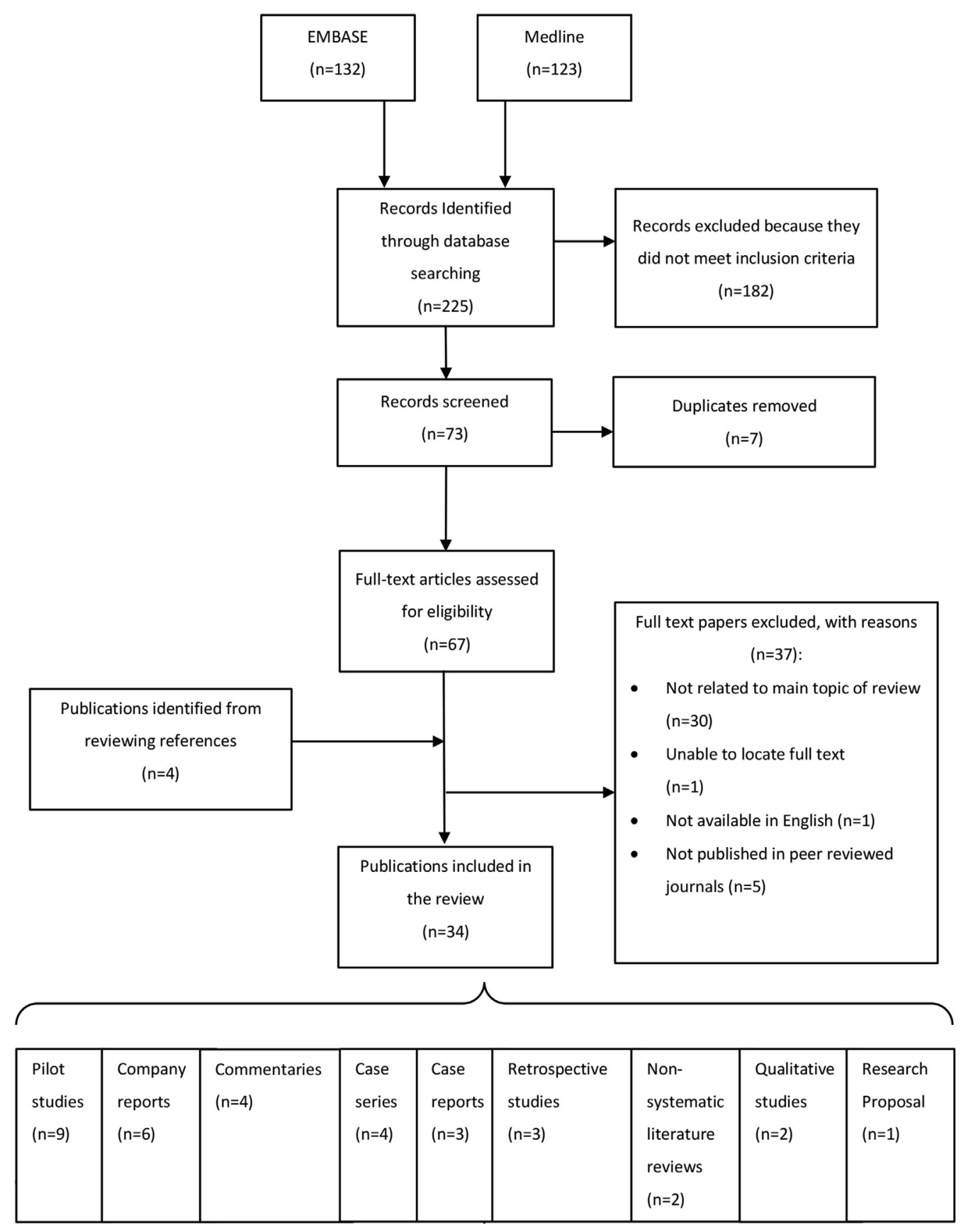

Figure 1. PRIMSA flow diagram.

used in remote environments, in particular the polar and maritime settings. All bases in the Antarctic had standard medical equipment, with larger stations having more advanced facilities such as plain radiography (x-ray) and ultrasound. ${ }^{25}$ The largest US research stations had a dermatology telemedical program and specialized equipment (eg, a dermatoscope), as well as facilities to perform biopsies and basic staining. ${ }^{26}$ Japan's Syowa station had operating facilities, wherein 2 appendectomies under spinal anesthesia had been performed. ${ }^{5,39}$ ECGs were available on many ships and have been advocated internationally. French merchant or fishing ships navigating without limitation of destination or time and all passenger vessels have been mandated to carry an ECG machine and defibrillator (which can be used by a nurse or second captain). ${ }^{20}$ Cameras, readily available in 
Table 2. Publications by article type and environment

\begin{tabular}{|c|c|c|c|c|c|}
\hline Type of article & Maritime & Antarctic & Mountain & Jungle & $\begin{array}{l}\text { Multiple austere } \\
\text { environments }\end{array}$ \\
\hline $\begin{array}{l}\text { Case reports and } \\
\text { case series }\end{array}$ & $\begin{array}{l}\text { Dehours et al, } 2016^{9} \\
\text { Dehours et al, } 2017^{10} \\
\text { Lee et al, } 2015^{11} \\
\text { Lefkowitz and } \\
\quad \text { Ridge, } 2016^{12}\end{array}$ & $\begin{array}{l}\text { Hyer, } 1999^{13} \\
\text { Otto et al, } 2012^{2}\end{array}$ & $\begin{array}{l}\text { White and } \\
\text { Angood, } 1999^{14}\end{array}$ & - & - \\
\hline Commentaries & $\begin{array}{l}\text { Batty, 2002 } \\
\text { Dahl, 2014 } \\
\text { Guitton, 2015 } \\
\text { Horneland, 2009 }\end{array}$ & - & - & - & - \\
\hline Qualitative studies & $\begin{array}{l}\text { Dehours et al, } 2012^{18} \\
\text { Norum et al, } 2002^{19}\end{array}$ & - & - & - & - \\
\hline Retrospective studies & Vallé et al, $2010^{20}$ & Otto et al, $2013^{21}$ & - & - & $\begin{array}{l}\text { Waterman } \\
\quad \text { et al, } 2014^{22}\end{array}$ \\
\hline Company reports & $\begin{array}{l}\text { Mahdi and } \\
\text { Amenta, } 2016^{23}\end{array}$ & $\begin{array}{l}\text { Grant, } 2004^{24} \\
\text { Ohno et al, } 2012^{5} \\
\text { Pillon and Todini, } \\
\quad 2004^{25} \\
\text { Siderfin et al, } 1995^{1} \\
\text { Sun et al, } 2010^{26}\end{array}$ & - & - & - \\
\hline Pilot studies & $\begin{array}{l}\text { Nikolić et al, } \\
2006^{27}\end{array}$ & $\begin{array}{l}\text { Bonnardot and } \\
\text { Rainis, } 2009^{28}\end{array}$ & $\begin{array}{l}\text { McBeth et al, } \\
2010^{29} \\
\text { Otto and Pipe, } \\
1997^{30} \\
\text { Otto et al, } 2009^{31} \\
\text { Satava, } 2003^{32}\end{array}$ & $\begin{array}{l}\text { Latifi et al, } \\
2009^{33}\end{array}$ & $\begin{array}{l}\text { Kirkpatrick } \\
\text { et al, } 2017^{34} \\
\text { McBeth et al, } \\
2011^{35}\end{array}$ \\
\hline $\begin{array}{l}\text { Nonsystematic } \\
\text { literature } \\
\text { reviews }\end{array}$ & - & - & - & - & $\begin{array}{l}\text { Nelson et al, } \\
2011^{36} \\
\text { Nelson and } \\
\text { Sanghvi, } 2016^{37}\end{array}$ \\
\hline Research proposal & - & - & - & - & $\begin{array}{l}\text { Kirkpatrick } \\
\text { et al, } 2015^{38}\end{array}$ \\
\hline $\begin{array}{l}\text { Total no. of articles } \\
\text { per environment }\end{array}$ & 13 & 9 & 5 & 1 & 6 \\
\hline
\end{tabular}

many environments, have been used to aid diagnoses. The transmission of photos via email has been particularly well reported at sea by the Italian TMAS and in the Antarctic environment by an Antarctic dermatology program. $^{23,26}$ In addition, 2 case series ${ }^{9,10}$ and 1 case report $^{12}$ illustrated the use of photos to assist in the diagnosis and management of skin conditions and minor trauma and to transmit ECGs in the maritime environment. Cases included remote follow-up of a burn injury of a patient at sea and a diagnosis of toxic epidermal necrolysis that lead to a patient's aeromedical evacuation.

\section{Discussion}

Defining "expedition" was a key factor in determining which articles were included or excluded from this review. Although an expedition has been described as "a journey with a purpose,"3 that definition might also have included a trip to the grocery store. Therefore, the nature of the journey must be further clarified by the austerity or remoteness of its environment. However, even within the same geographical setting, "remoteness" is as much a question of facilities as linear distance from help. For example, a fishing vessel sailing in the same waters as a cruise ship might be considered more "remote," given the fishing vessel's relative paucity of medical equipment and experience. The same might be said of Antarctic bases, which varied in their facilities depending on the size of the base and the population it served.

A working definition might therefore be a journey with a purpose, but also one over a set timeframe, with limited medical provision and barriers to rapidly transferring a patient to definitive care. This formed the basis 
Table 3. Publications categorized by topic ${ }^{a}$

\begin{tabular}{|c|c|}
\hline Topic & Publications \\
\hline $\begin{array}{l}\text { General use of } \\
\text { telemedicine }\end{array}$ & $\begin{array}{l}\text { Hyer, } 1999^{13} \\
\text { Horneland, } 2009^{4} \\
\text { Guitton, } 2015^{17} \\
\text { Norum et al, } 2002^{19}\end{array}$ \\
\hline Company reports & $\begin{array}{l}\text { Mahdi and Amenta, } 2016^{23} \\
\text { Pillon and Todini, } 2004^{25} \\
\text { Ohno et al, } 2012^{5} \\
\text { Grant, } 2004^{24} \\
\text { Siderfin et al, } 1995^{1} \\
\text { Sun et al, } 2010^{26}\end{array}$ \\
\hline Specialties & $\begin{array}{l}\text { Dahl, } 2014^{16} \\
\text { Lee et al, } 2015^{11} \\
\text { Sun et al, } 2010^{26} \\
\text { Waterman et al, } 2014^{22}\end{array}$ \\
\hline Feasibility of equipment & $\begin{array}{l}\text { Otto and Pipe, } 1997^{30} \\
\text { Latifi et al, } 2009^{33} \\
\text { Satava, 2003 } \\
\text { McBeth et al, } 2010^{29} \\
\text { Bonnardot and Ranis, } 2009^{28}\end{array}$ \\
\hline Video conferencing & $\begin{array}{l}\text { White and Angood, } 1999^{14} \\
\text { Lee et al, } 2015^{11} \\
\text { Ohno et al, } 2012^{5} \\
\text { Latifi et al, } 2009^{33}\end{array}$ \\
\hline Photography & $\begin{array}{l}\text { Lefkowitz and Ridge, } 2016^{12} \\
\text { Dehours et al, } 2016^{9} \\
\text { Dehours et al, } 2017^{10}\end{array}$ \\
\hline Ultrasound & $\begin{array}{l}\text { Otto et al, } 2012^{2} \\
\text { Otto et al, } 2013^{21} \\
\text { Nelson and Sanghvi, } 2016^{37} \\
\text { Nelson et al, } 2011^{36} \\
\text { McBeth et al, 2011 } \\
\text { McBeth et al, 2010 } \\
\text { Otto et al, 2009 } \\
\text { Nikolić et al, } 2006^{27}\end{array}$ \\
\hline $\begin{array}{l}\text { Radiology } \\
\text { ECG }\end{array}$ & $\begin{array}{l}\text { Batty, } 2002^{15} \\
\text { Dehours et al, } 2017^{10} \\
\text { Horneland, 2009 } \\
\text { Vallé et al, } 2010^{20}\end{array}$ \\
\hline $\begin{array}{l}\text { Telemonitoring } \\
\text { User satisfaction } \\
\text { Telementoring }\end{array}$ & $\begin{array}{l}\text { Satava, } 2003^{32} \\
\text { Dehours et al, } 2012^{18} \\
\text { Kirkpatrick et al, } 2017^{34} \\
\text { Kirkpatrick et al, } 2015^{38} \\
\text { McBeth et al, 2011 } \\
\text { McBeth et al, 2010 } \\
\text { Otto et al, 2009 }\end{array}$ \\
\hline
\end{tabular}

${ }^{\mathrm{a}}$ Some publications may appear in more than one category.

of the review. It was believed that cruise ship medicine met this definition; although rural, aviation, space, and disaster medicine all shared some of its scope, they were excluded. Rural populations and those affected by natural disasters involved settled populations rather than those making a journey and so were on an "infinite" timeframe. Medical decision-making in terrestrial aviation revolved primarily around whether an aircraft should be diverted to land and, as such, operated on a much shorter timescale and with different constraints compared with most expeditions. In space medicine, telemedical research has typically been directed toward exploratory class missions to the moon and Mars. Consequently, the challenges considered were different from those on Earth (eg, microgravity, communication delays of up to $15 \mathrm{~min}$, and the length and evacuation costs of the missions themselves). This led to a presumption of better technology and skills on the part of systems and operators in the space medicine literature, in comparison to work from terrestrial expeditions.

\section{CHANNELS OF COMMUNICATION AND THE RISE OF VIDEOCONFERENCING}

Telemedicine is possible as long as there is communication, be it by fax, email, telephone, radio, or videoconferencing. Although verbal communication may have been at the heart of telemedicine, images and other media have assisted consultations. This has been possible for over $20 \mathrm{y}$ in even the most remote parts of the world, as demonstrated by a pilot study published in 1997 in which ECG tracings, audio clips, videos, and still images of healthy participants were transmitted successfully during an expedition on Mount Logan. ${ }^{30}$ With technological advances, videoconferencing for real-time telemedical consultations has become available in remote locations including at sea, ${ }^{11}$ in the Antarctic,${ }^{5}$ in the mountains, ${ }^{14}$ and in the jungle. ${ }^{33}$ Routine videoconference teleconsultations were conducted monthly at Japan's Syowa Antarctic station. ${ }^{5}$ Even before 1999, videoconferencing was used for daily ward rounds at Everest Base Camp ${ }^{14}$ and while accompanying Martin Strel on his swim of the length of the Amazon river (129 real-time consultations were undertaken during the journey). ${ }^{33}$ Videoconferencing has allowed remote doctors to speak directly to both patients and local care providers, observe examinations, and guide care providers through simple procedures and examinations. ${ }^{5}$ Its advantages over voice communication were demonstrated in a case report of a mariner expressing suicidal thoughts at sea. Unlike voice calls alone, videoconferencing allowed the psychiatrist to perform a full psychiatric assessment including assessment of appearance and behavior as part of mental state examination. Mania was diagnosed, and psychiatric hospitalization abroad could be avoided because the patient was deemed safe to fly. ${ }^{11}$

\section{PREVENTION OF UNNECESSARY EVACUATION}

As well as facilitating diagnosis and management of patients, telemedicine has been effective at preventing 
unnecessary evacuations (eg, when used to diagnose and treat pericarditis in a worker in the Antarctic ${ }^{2}$ and to manage an episode of supraventricular tachycardia in a passenger on a cruise ship). ${ }^{10}$ Its effectiveness was also demonstrated by a retrospective study in the Antarctic Amundsen-Scott and McMurdo research stations, where telemedicine combined with ultrasound was used to prevent 17 unnecessary evacuations out of 66 cases between 2002 and 2003. ${ }^{21}$ A retrospective study over 32 mo between 2009 and 2012 on an orthopedic teleconsultation program for the US military found that of 597 referrals, 26 evacuations were prevented. ${ }^{22}$ Although this may not be generalizable to the civilian population on expedition, given that the military has extensive access to medical facilities and personnel, it offered a good example of how specialist opinions via telemedicine could prevent unnecessary evacuations.

\section{ECGS}

The provision of ECG equipment on ships has been subject to debate, so the topic has been studied in more depth than in other environments. Those questioning the value of ECGs on ships believed them to be too difficult to perform accurately, risking false positives or negatives. ${ }^{4}$ However, studies have also illustrated their value, with case reports ${ }^{10}$ outlining scenarios in which ECGs facilitated decisions regarding initiation of treatment and evacuation. One example was the case of a passenger on a cruise with a supraventricular tachycardia of 220 beats $\min ^{-1}$, diagnosed remotely as Bouveret's disease junctional tachycardia by a cardiologist based on the ECG. Evacuation was avoided on the cardiologist's recommendation, and the patient was treated with amiodarone and outpatient follow-up on return. ${ }^{10}$ In a retrospective study on the use of ECGs on ships, ${ }^{20}$ of 179 cardiac presenting complaints identified in 2008 and 2009, ECG enabled diagnosis of 23 ST elevation myocardial infarctions, 21 non-ST elevation myocardial infarctions, and 15 arrhythmias. However, the same study also found that although $74 \%$ of vessels were equipped with an ECG machine, a small proportion (4 of 63) of ECGs could not be transmitted owing to either lack of equipment or transmission problems. ${ }^{20}$ Another study found that $23 \%$ of users $(n=30)$ had difficulties in recording ECGs and $17 \%(n=22)$ had difficulty with transmission. ${ }^{18}$ However, the value of ECG on ships appeared to outweigh its difficulties, and its ability to assist decision-making has been clearly demonstrated. Furthermore, although not every vessel may have had an ECG machine, it has still been beneficial for some ships to have been equipped to aid others. This was demonstrated in a case report in which the French TMAS directed a fishing vessel without ECG equipment to change course to another, better equipped ship after a fisherman onboard developed chest pain. ${ }^{10}$ Extensive anterior myocardial infarction was diagnosed and treated appropriately. ${ }^{10,20}$

\section{RADIOLOGY}

Remote imaging has been a valuable diagnostic tool, particularly in the management of trauma. The contribution of radiography and telemedicine to patient care in the Antarctic was demonstrated in a case series from 1995 where they were used to diagnose and manage a Colles fracture and a dislocated hip without evacuation. ${ }^{13}$ Because injury and trauma contribute to almost half of the medical consultations in the Antarctic, ${ }^{5}$ x-ray facilities have been particularly useful to Antarctic stations in reducing the burden of evacuations. A low-quality commentary from 2002 suggested introducing radiology facilities on cruise ships. ${ }^{15}$ Since then, $\mathrm{x}$-ray has become commonly available on cruise ships and is now recommended in the American College of Emergency Physicians' 2014 healthcare guidelines for cruise ship medical facilities. ${ }^{40}$

For those remote environments without access to x-ray facilities, portable ultrasound has been a developing tool for diagnosis. Two nonsystematic reviews ${ }^{36,37}$ published by the same author on the use of point-of-care ultrasound summarized the literature regarding the use of portable ultrasound in prehospital and austere environments. Fifteen of the included studies demonstrated the accuracy of portable ultrasound for diagnosing hemoperitoneum, pneumothorax, pericardial effusion, and abdominal aortic aneurysm in emergency department patients. ${ }^{37}$ One study that assessed the use of prehospital ultrasound in patients with blunt abdominal trauma found that management was changed in $30 \%(n=30)$ of patients. ${ }^{41}$ Eight studies were reported in which point-of-care ultrasound was used in austere environments including the Amazon jungle, the International Space Station, the Artic, and after a hurricane in a village of a developing country. The challenges of ultrasound examination in these environments were uncooperative patients, inadequate lighting, limited power supplies, lack of physical space, and time constraints. Despite these limitations, portable ultrasound remains a promising avenue for prehospital and remote environments owing to its portability, potential smartphone compatibility, and ability for remote interpretation of scans. ${ }^{37}$

In the Antarctic, a case report ${ }^{2}$ and a retrospective study ${ }^{21}$ have been published on the use of ultrasound for telemedicine at McMurdo and Amundsen-Scott research stations. Both reported the use of store-and-forward interpretation (wherein images were transferred via email to be interpreted after completion of the examination) and 
real-time interpretation (where the remote doctor visualized the examination while it was in progress). Store-andforward was adequate in the majority of cases, and realtime assessments were arranged when necessary. In 51 of 62 store-and-forward scans, ultrasound contributed positively to patient management, leading to initiation, confirmation, or prevention of treatment and establishing need for further investigations, second opinion, or evacuation. In fact, evacuation was prevented in $26 \%$ of cases. However, 2 scans did not provide enough diagnostic information and 7 gave false positives or negatives. This study illustrated the usefulness of ultrasound for patient management but also its dependence on operator skill; examinations performed by physicians with basic ultrasound training had the potential to generate more misleading scans than those performed by a skilled sonographer. $^{21}$

\section{REMOTE TELEMENTORED ULTRASOUND}

Ultrasound is operator dependent. It takes several years to train a sonographer, and the Royal College of Radiologists recommends that clinicians who perform focused assessments with sonography for trauma scans should first have undertaken at least 50 examinations under supervision. For clinicians to become competent at ultrasound examinations of other systems, even more repetitions may be required. ${ }^{42}$ Where a local care provider on an expedition may not be competent at performing an ultrasound, the possibility of using telementoring, where the local ultrasound operator is guided by a remote expert, has been explored. Remote telementored ultrasound (RTUS) has been used successfully in the Antarctic, when a physician with basic ultrasound training was guided by a cardiology team in Texas via video-teleconferencing to obtain optimal images for echocardiography. This allowed the diagnosis of pericarditis to be confirmed and its progression assessed. The effusion was shown to be resolving, which avoided evacuation and allowed the patient to be managed medically in the Antarctic. ${ }^{2}$ RTUS was also described in a case report published in 1999 at Mount Everest Base Camp where videoconferencing facilitated an ultrasound chest examination that demonstrated consolidation in the patient's left lung. ${ }^{14}$ Since then, RTUS has been shown to be able to provide high-quality images of multiple organ systems. ${ }^{43}$

Three pilot studies ${ }^{29,31,35}$ explored the use of RTUS in remote environments using specifically designed equipment that included a portable ultrasound and a headmounted web camera that allowed the remote expert to visualize the examiner's hands, the patient, and ultrasound images for 1-way video and 2-way audio communication. A variety of operators, locations, and ultrasound examinations were tested. Two climbers with no ultrasound experience were guided remotely to perform lung ultrasounds in an expedition medical tent at Mount Everest's advanced base camp on 2 patients who were acclimatizing. As well as real-time audio guidance, the climbers were given cue cards for visual guidance on probe position and were able to perform the examination without difficulty. The images were suitable for excluding pneumothorax and quantifying the presence of comet tail artifacts, which are a sign of high-altitude pulmonary edema. ${ }^{31}$ Another pilot study assessed the feasibility of RTUS in 8 locations, including 2 remote outdoor environments (Banff and Lake Louise). ${ }^{35}$ Focused assessments with sonography for trauma scans were performed on healthy volunteers by ultrasound operators with experience varying from medical trainee to nonmedical personnel. The presence of lung sliding to exclude pneumothorax was demonstrated by all users, ${ }^{35}$ but the study did not comment on whether views of different structures were adequate to diagnose or exclude other pathology. Although these pilot studies have demonstrated that the technology for RTUS in remote environments is available, further studies are needed to assess its effectiveness at diagnosing different pathologies, as well as what types of expeditions would benefit from investing in RTUS and how much training the local user would require.

The issue of training was explored in a pilot study of ships' officers being taught to use ultrasound independently for store-and-forward interpretation. Unfortunately, a large proportion of their scans gave false negative results, and some could not be interpreted because the organ in question was not visualized. ${ }^{27}$ Although the study was limited because the seafarers only had $30 \mathrm{~min}$ of practical teaching, RTUS may be a more effective use of teaching resources; independent sonography skills would deteriorate without regular practice, and false negatives may have adverse effects on patient care.

\section{TELEMENTORING FOR DAMAGE CONTROL SURGERY}

The use of telementoring to assist in damage control laparotomies in austere environments for traumatic noncompressible truncal intracavity hemorrhage has been explored. ${ }^{38}$ In a pilot study, military medical technicians performed damage control laparotomies on a surgical simulator with the assistance of telementoring via 1-way video and 2-way audio communication. The subjects were split into those who performed the surgery with and without telementoring. The results were not supportive; there was no difference in blood loss between the 2 groups, and none of the candidates could close the laparotomy wound. ${ }^{34}$ The report itself was of poor evidential 
quality because the number of participants was not stated and the methodology was unclear. Questions also remained regarding the provision of anesthesia. Furthermore, damage control surgery is part of a chain of resuscitation, rather than an end in itself. Despite these limitations, the use of telementoring for surgery in remote environments still has potential, although it may be more pertinent for battlefield medicine and space medicine than for the expeditionary focus of this review.

\section{AREAS FOR FURTHER DEVELOPMENT}

The success of telemedicine depends on multiple factors, including the local equipment and caregiver, the remote physician's expertise, and, of course, the communication between both parties. A number of maritime studies have suggested improvements that would enhance patient care and which may be extrapolated to other remote environments. First, education of both local care providers and remote physicians should be promoted. A user satisfaction survey on telemedicine found that seafarers were keen for training to be focused on isolated environments, ${ }^{18}$ and interviews from caregivers on recommendations for maritime telemedicine suggested that healthcare providers needed more awareness of the working conditions in remote environments. ${ }^{19}$ The provision of electronic medical references onboard ships has been proposed, and it has been suggested that the process of contacting telemedicine providers should be simplified because it can be confusing for care providers if there are too many methods to contact help. ${ }^{19}$ Equipment for monitoring and telemedical communication should be optimized. ${ }^{19}$ Telemedical carts have been developed by the Italian TMAS that included standard monitoring equipment, as well as a glucometer, 12-lead ECG, spirometer, electronic stethoscope, and camera that could be easily linked to a provided computer. ${ }^{23}$ Further work will be needed to determine whether this equipment has a quantifiable impact on patient care.

An article published in 2019 by Australian Broadcasting Corporation News highlighted the benefits of training of local care providers, when the sole doctor at an Australian Antarctic base broke a bone in her dominant hand during the winter season. Via telemedicine, a hand surgeon diagnosed the severity of the injury and advised treatment. The hand surgeon and an anesthesiologist were able to remotely guide local surgical lay assistants (nonmedical personnel trained to assist a doctor) via a videolink and $\mathrm{x}$-ray imaging to perform a nerve block, reduce the bone, and apply a plaster cast. Part of this procedure's success was attributed to the $2 \mathrm{wk}$ of hospital training received by the surgical lay assistants before deployment, along with monthly refresher training by the base doctor. ${ }^{44}$ This example illustrated the success of a telemedical system, rather than simply telemedical technology. The combination of planning and regular training with adequate medical and communication facilities and appropriate remote expertise allowed the successful diagnosis and treatment of the patient.

Telemetry (real-time patient monitoring) and telementoring (remote guidance of a less-experienced care provider by an expert) both have potential to contribute to the safety and success of expeditions. Wearable telemetry with a global positioning system for routine monitoring has been developed and made commercially available, ${ }^{32,45}$ although its impact on patient and expedition outcomes has not yet been fully assessed. Another application, yet to be tested, is the use of real-time monitoring to provide anesthetic support in the Antarctic to assist local doctors performing invasive procedures. ${ }^{24}$ For telementoring, seafarers have enthusiastically suggested the development of videoconferencing on ships to guide nonmedics in performing medical procedures ${ }^{9}$ such as joint relocation and suturing. ${ }^{17}$ However, advocating the approach would require further research into its feasibility, effectiveness, and potential for harm (along with its associated medicolegal ramifications).

In the future, drones may be employed as a link in a telemedicine system because they are able to access remote locations promptly. Drones have been used for surveillance in the initial assessment of disasters, along with transport of equipment such as automated external defibrillators, lab specimens, and blood products. ${ }^{46-48}$ However, the role of drones in telemedicine remains largely unproven. One study demonstrated the feasibility of using a drone to assist in telemedicine by providing a wireless communication network between a surgeon and a robot to perform telesurgery when the operator was located remotely from the site of the patient. ${ }^{49}$ Another article from the gray literature describes a drone with videoconferencing capabilities and the capacity to deliver medical equipment, designed to provide telemedical assistance. ${ }^{48}$ Drone technology has been improving rapidly, but, like other promising new avenues of telemedicine, its role within a telemedical system requires exploration and evaluation.

\section{LIMITATIONS}

Many of the articles included in this review were small studies in specific environments. Although some environments were better reported than others, some concepts were generalizable. For example, telepsychiatry by videoconferencing may only have been documented in the maritime environment, but it is likely to be possible in any location with access to videoconferencing. 
Although the inclusion and exclusion criteria have been clearly stated, the definition of an "expedition" will always be somewhat subjective. The broad definition of "remote and austere environments" maximized the likelihood of relevant studies being located. Only articles available in the English language were included. As telemedical services have been provided and used by a multitude of nations, restricting the search to a single language limited the potential for articles to be identified. Additionally, because technology has been the key driver in telemedicine, the earliest acceptable date of publication of included articles was a matter of debate. For example, 4 of the Antarctic reports ${ }^{1,13,24,25}$ included were written before the introduction of INTELSAT in 2004, which greatly improved satellite bandwidth and enabled videoconferencing. INTELSAT also no longer restricted communications to certain times of day (unlike the previous satellite, INMARSAT). ${ }^{5}$

\section{Conclusions}

Telemedicine on expeditions can be used to initiate treatment, follow up with patients remotely, and decide on the necessity of evacuation. Indeed, telemedicine's role in the prevention of unnecessary evacuation was a consistent thread running through the publications in this review. With ever-improving satellite communications, telemedicine is available anywhere in the world. Once restricted to voice communication alone, increasing data bandwidth has expanded the scope of telemedicine to include images, videos, and diagnostic information from point-of-care testing such as ultrasound. Videoconferencing has been used successfully in the most remote of locations for patient assessment, as well as facilitating telementoring.

Although telemedicine has already assisted many people in remote locations, it is important to continue developing this field and critically appraising its success to ensure that delivery of healthcare in these environments is of the highest standard possible. New technologies must be shown to do more than simply function in a remote environment. They should demonstrate improved patient, practitioner, or expedition outcomes within a telemedical system that includes training, equipment provision, and follow-up care.

\footnotetext{
Author Contributions: Study concept and design (LT); acquisition and analysis of the publications (LT); drafting of the manuscript (LT); critical revision of the manuscript (MW); and approval of final manuscript (LT, MW).

Financial/Material Support: None.

Disclosures: None.
}

\section{References}

1. Siderfin CD, Haston W, Milne AH. Telemedicine in the British Antarctic Survey Medical Unit. J Telemed Telecare. 1995;1(2):63-8.

2. Otto CA, Shemenski R, Drudi L. Real-time tele-echocardiography: diagnosis and management of a pericardial effusion secondary to pericarditis at an Antarctic research station. Telemed J E Health. 2012;18(7):521-4.

3. Johnson C, Anderson S, Dallimore J, Winser S, Warrell DA. Oxford Handbook of Expedition and Wilderness Medicine. OUP Oxford; 2008.

4. Horneland AM. Maritime telemedicine - where to go and what to do. Int Marit Health. 2009;60(1-2):36-9.

5. Ohno G, Watanabe K, Okada Y, Higuchi K. Practical experience of telehealth between an Antarctic station and Japan. J Telemed Telecare. 2012;18(8):473-5.

6. Roever L, Ocke Reis P. Critical appraisal of a case report. Evid Based Med Pract. 2015;1(1):e103.

7. Moola S, Munn Z, Tufanaru C, Aromataris E, Sears K, Sfetcu R, et al. Chapter 7: Systematic reviews of etiology and risk. In: Aromataris E, Munn Z, eds. Joanna Briggs Institute Reviewer's Manual. The Joanna Briggs Institute, 2017. Available at from https://reviewersmanual. joannabriggs.org/. Accessed November 17, 2019.

8. Critical Appraisal Skills Programme. CASP qualitative checklist. Available from: http://www.casp-uk.net/ checklists. Accessed November 17, 2019.

9. Dehours E, Tourneret M-L, Roux P, Tabarly J. Benefits of photograph transmission for trauma management in isolated areas: cases from the French tele-medical assistance service. Int Marit Health. 2016;67(2):83-7.

10. Dehours E, Saccavini A, Roucolle P, Roux P, Bounes V. Added value of sending photograph in diagnosing a medical disease declared at sea: experience of the French TeleMedical Assistance Service. Int Marit Health. 2017;68(2):122-5.

11. Lee A, Sikka N, O’Connell F, Dyer A, Boniface K, Betz J. Telepsychiatric assessment of a mariner expressing suicidal ideation. Int Marit Health. 2015;66(1):49-51.

12. Lefkowitz RY, Ridge GE. Paederus dermatitis in a seafarer diagnosed via telemedicine collaboration. J Travel Med. 2016;23(3):taw017.

13. Hyer RN. Telemedical experiences at an Antarctic station. J Telemed Telecare. 1999;5(Suppl 1):S87-9.

14. White AP, Angood P. Advancing technologies in clinical medicine: the Yale-Mount Everest telemedicine project. Yale J Biol Med. 1999;72(1):19-27.

15. Batty V. Teleradiology-an integrated solution. Int Marit Health. 2002;53(1-4):122-6.

16. Dahl E. Briefing notes on maritime teledermatology. Int Marit Health. 2014;65(2):61-4.

17. Guitton MJ. Telemedicine at sea and onshore: divergences and convergences. Int Marit Health. 2015;66(1):18-21.

18. Dehours E, Vallé B, Bounes V, Girardi C, Tabarly J, Concina F, et al. User satisfaction with maritime telemedicine. J Telemed Telecare. 2012;18(4):189-92. 
19. Norum J, Moksness SG, Larsen E. A Norwegian study of seafarers' and rescuers' recommendations for maritime telemedicine services. J Telemed Telecare. 2002;8(5):264-9.

20. Vallé B, Camelot D, Bounes V, Parant M, Battefort F, Ducassé J-L, et al. Cardiovascular diseases and electrocardiogram teletransmission aboard ships: the French TMAS experience. Int Marit Health. 2010;62(3):129-36.

21. Otto C, Shemenski R, Scott JM, Hartshorn J, Bishop S, Viegas S. Evaluation of tele-ultrasound as a tool in remote diagnosis and clinical management at the Amundsen-Scott South Pole Station and the McMurdo Research Station. Telemed J E Health. 2013;19(3):186-91.

22. Waterman BR, Laughlin MD, Belmont Jr PJ, Schoenfeld AJ, Pallis MP. Enhanced casualty care from a global military orthopaedic teleconsultation program. Injury. 2014;45(11):1736-40.

23. Mahdi SS, Amenta F. Eighty years of CIRM. A journey of commitment and dedication in providing maritime medical assistance. Int Marit Health. 2016;67(4):187-95.

24. Grant IC. Telemedicine in the British Antarctic survey. Int J Circumpolar Health. 2004;63(4):356-64.

25. Pillon S, Todini AR. eHealth in Antarctica: a model ready to be transferred to every-day life. Int $J$ Circumpolar Health. 2004;63(4):436-42.

26. Sun A, Lanier R, Diven D. A review of the practices and results of the UTMB to South Pole teledermatology program over the past six years. Dermatol Online J. 2010;16(1):16.

27. Nikolić N, Mozetić V, Modrcin B, Jaksić S. Might telesonography be a new useful diagnostic tool aboard merchant ships? A pilot study. Int Marit Health. 2006;57(1-4):198-207.

28. Bonnardot L, Rainis R. Store-and-forward telemedicine for doctors working in remote areas. J Telemed Telecare. 2009;15(1):1-6.

29. McBeth PB, Hamilton T, Kirkpatrick AW. Cost-effective remote iPhone-teathered telementored trauma telesonography. J Trauma. 2010;69(6):1597-9.

30. Otto C, Pipe A. Remote, mobile telemedicine: the satellite transmission of medical data from Mount Logan. J Telemed Telecare. 1997;3(Suppl 1):84-5.

31. Otto C, Hamilton DR, Levine BD, Hare C, Sargsyan AE, Altshuler $\mathrm{P}$, et al. Into thin air: extreme ultrasound on $\mathrm{Mt}$ Everest. Wilderness Environ Med. 2009;20(3):283-9.

32. Satava RM. Telemedicine and real-time monitoring of climbers. Curr Probl Dermatol. 2003;32:141-7.

33. Latifi R, de Leonni Stanonik M, Merrell RC, Weinstein RS. Telemedicine in extreme conditions: supporting the Martin Strel Amazon swim expedition. Telemed $J$ E Health. 2009;15(1):93-100.

34. Kirkpatrick AW, McKee JL, McBeth PB, Ball CG, LaPorta A, Broderick T, et al. The Damage Control Surgery in Austere Environments Research Group (DCSAERG): a dynamic program to facilitate real-time telementoring/telediagnosis to address exsanguination in extreme and austere environments. J Trauma Acute Care Surg. 2017;83(1 Suppl 1):S156-63.

35. McBeth PB, Crawford I, Blaivas M, Hamilton T, Musselwhite K, Panebianco N, et al. Simple, almost anywhere, with almost anyone: remote low-cost telementored resuscitative lung ultrasound. J Trauma. 2011;71(6):1528-35.

36. Nelson BP, Melnick ER, Li J. Portable ultrasound for remote environments, Part I: feasibility of field deployment. J Emerg Med. 2011;40(2):190-7.

37. Nelson BP, Sanghvi A. Out of hospital point of care ultrasound: current use models and future directions. Eur J Trauma Emerg Surg. 2016;42(2):139-50.

38. Kirkpatrick AW, LaPorta A, Brien S, Leslie T, Glassberg E, McKee J, et al. Technical innovations that may facilitate realtime telementoring of damage control surgery in austere environments: a proof of concept comparative evaluation of the importance of surgical experience, telepresence, gravity and mentoring in the conduct of damage control laparotomies. Can J Surg. 2015;58(3 Suppl 3):S88-90.

39. Ikeda A, Ohno G, Otani S, Watanabe K, Imura S. Disease and injury statistics of Japanese Antarctic research expeditions during the wintering period: evaluation of 6837 cases in the 1st-56th parties - Antarctic health report in 1956-2016. Int J Circumpolar Health. 2019;78(1):1611327.

40. American College of Emergency Physicians. Health care guidelines for cruise ship medical facilities. Available at: https://www.acep.org/globalassets/new-pdfs/preps/2014health-care-guidelines-for-cruise-ship-medical-facilitiesprep.pdf. Accessed April 3, 2020.

41. Walcher F, Weinlich M, Conrad G, Schweigkofler U, Breitkreutz R, Kirschning T, et al. Prehospital ultrasound imaging improves management of abdominal trauma. $\mathrm{Br} J$ Surg. 2006;93(2):238-42.

42. The Royal College of Radiologists. Ultrasound training recommendations for medical and surgical specialties. 2nd ed. London: The Royal College of Radiologists; 2012.

43. Hurst VW, Peterson S, Garcia K, Ebert D, Ham D, Amponsah D, et al. Concept of operations evaluation for using remote-guidance ultrasound for exploration spaceflight. Aerosp Med Hum Perform. 2015; 86(12):1034-8.

44. Clarke C. Tradies fixed a doctor's hand in Antarctica - and now medical experience like this will be shared with the world. Australian Broadcasting Corporation. Available at: https://www.abc.net.au/news/2019-03-28/antarctic-medicineexperience-to-be-shared/10945296. Accessed April 3, 2020.

45. Li RT, Kling SR, Salata MJ, Cupp SA, Sheehan J, Voos JE. Wearable performance devices in sports medicine. Sports Health. 2016;8(1):74-8.

46. Rosser Jr JC, Vignesh V, Terwilliger BA, Parker BC. Surgical and medical applications of drones: a comprehensive review. JSLS. 2018;22(3):e2018.00018.

47. Bhatt K, Pourmand A, Sikka N. Targeted applications of unmanned aerial vehicles (drones) in telemedicine. Telemed $J$ E Health. 2018;24(11):833-8.

48. Balasingam M. Drones in medicine-The rise of the machines. Int J Clin Pract. 2017;71(9):10.

49. Harnett BM, Doarn CR, Rosen J, Hannaford B, Broderick TJ. Evaluation of unmanned airborne vehicles and mobile robotic telesurgery in an extreme environment. Telemed J E Health. 2008;14(6):539-44. 